\title{
Age-dependency of surfactant phospholipids and surfactant protein $A$ in bronchoalveolar lavage fluid of children without bronchopulmonary disease
}

\author{
F. Ratjen*, B. Rehn**, U. Costabel+, J. Bruch**
}

Age-dependency of surfactant phospholipids and surfactant protein A in bronchoalveolar lavage fluid of children without bronchopulmonary disease. F. Ratjen, B. Rehn, U. Costabel, J. Bruch. CERS Journals Ltd 1996.

ABSTRACT: Whilst alterations in surfactant components of bronchoalveolar lavage fluid (BALF) have been described in a variety of pulmonary diseases in adults, no information is available on the surfactant composition in children beyond the neonatal period. In order to obtain reference values for the paediatric age group, we have studied phospholipid profiles of BALF in children without pulmonary disease.

The study population consisted of 38 children aged 3-15 yrs (mean \pm SD $8 \pm 4$ yrs) undergoing elective surgery for nonpulmonary illnesses. Surfactant composition was analysed by high pressure liquid chromatography using both an ultraviolet and a light-scattering detector.

Total phospholipid concentration was higher in children under 8 yrs of age and decreased with age. In contrast, the total protein concentration remained constant throughout the age range. No age-related changes in the relative composition of phospholipid fractions could be observed. Surfactant protein A concentrations were highly variable in all age groups.

This study provides the first data on surfactant components in bronchoalveolar lavage fluid of healthy children and will be the basis for future studies of children with pulmonary diseases.

Eur Respir J., 1996, 9, 328-333.
Depts of *Paediatrics and **Occupational Medicine, University of Essen, Essen, Germany. +Dept of Pneumonology and Allergy, Ruhrlandklinik, Essen, Germany.

Correspondence: F. Ratjen

Zentrum für Kinder - und Jugendmedizin Universitätsklinikum Essen

Hufelandstr. 55

D-45122 Essen

Germany

Keywords: Bronchoalveolar lavage children

surfactant phospholipids

surfactant protein A

Received: May 181995

Accepted after revision October 251995
Pulmonary surfactant is a complex mixture of phospholipids and proteins that act to reduce the surface tension within the alveolus and are essential for the maintenance of normal pulmonary function. Deficiency of surfactant in neonates is known to cause the respiratory distress syndrome (RDS) [1], which can be treated successfully with replacement of exogenous surfactant material [2]. Recent studies utilizing bronchoalveolar lavage (BAL) have demonstrated that the total phospholipid concentrations as well as the ratio of phophatidylglycerol to phosphatidylinositol (PG/PI) are decreased in patients with the adult respiratory distress syndrome $[3,4]$ and in respiratory failure due to trauma $[5,6]$. A reduction in the PG/PI ratio has also been observed in a variety of interstitial lung diseases [7-9]. Total phospholipid concentrations of bronchoalveolar lavage fluid (BALF) have been found to be diminished in patients with acquired immune deficiency syndrome (AIDS) both with and without Pneumocystis carinii pneumonia [10, 11]. BALF phospholipids are also reduced in cystic fibrosis patients due to phospholipases produced by Pseudomonas species that inhibit surfactant function [12, 13].

Few data exist concerning BALF phospholipids in children beyond the neonatal period. Abnormalities of surfactant or one of its constituents have been described in the sudden infant death syndrome $[14,15]$, in infants with bronchopulmonary dysplasia [16], and in children with recurrent cyanotic episodes [17]. Studies of the phospholipid composition in paediatric lung diseases have been difficult to interpret, since reference values for this age group are lacking. As part of a study to define BALF constituents in childhood, we have investigated the composition of surfactant in children without pulmonary disease.

\section{Material and methods}

The study population consisted of 38 children aged 3-15 yrs (mean \pm SD $8 \pm 4$ yrs). All children were undergoing elective surgery for nonpulmonary illnesses (table 1). Children with an upper respiratory tract infection in the preceding 3 months, a lower respiratory tract infection or a history of hyperreactive airway disease were excluded from this study. The study was approved by the Ethics Committee of our institution. Written informed consent from both parents was obtained in all cases. 
Table 1. - Diagnosis and operative procedure of children undergoing $\mathrm{BAL}$

\begin{tabular}{lll}
\hline Diagnosis & Operative procedure & $\mathrm{n}$ \\
\hline Hypertrophy of adenoids & Adenectomy & 9 \\
Hypertrophy of tonsils & Tonsillectomy & 7 \\
Hypospadias & Correction & 7 \\
Retentio testis & Orchidopexy & 5 \\
Vesicoureteral reflux & Correction & 3 \\
Conductive deafness & Tympanoplasty & 2 \\
Nasal fracture & Correction & 1 \\
Nasal septum deviation & Correction & 1 \\
Parotic cyst & Exstirpation & 1 \\
Urethra duplex & Correction & 1 \\
Epispadia & Correction & 1
\end{tabular}

BAL: bronchoalveolar lavage

\section{Bronchoalveolar lavage}

Bronchoalveolar lavage (BAL) was performed under general anaesthesia and tracheal intubation. All children received flunitrazepam $\left(0.04-0.05 \mathrm{mg} \cdot \mathrm{kg}^{-1}\right.$ body weight (BW)) orally $1 \mathrm{~h}$ prior to the procedure. In children under 6 yrs of age, anaesthesia was initiated via inhalation of a nitrous oxide-oxygen mixture with 2.5 volume (vol) \% halothane. Subsequently, a venous access was inserted and atropine $\left(0.01 \mathrm{mg} \cdot \mathrm{kg}^{-1} \mathrm{BW}\right)$, vecoronium $(0.05$ $\left.\mathrm{mg} \cdot \mathrm{kg}^{-1} \mathrm{BW}\right)$ and alfentanil $\left(0.05 \mathrm{mg} \cdot \mathrm{kg}^{-1} \mathrm{BW}\right)$ were given intravenously. The halothane concentration was then reduced to 1.5 vol \%. In children older than 6 years a venous access was inserted first and methohexitone 1-1.5 $\mathrm{mg} \cdot \mathrm{kg}^{-1} \mathrm{BW}$ was given followed by atropine, vecoronium and alfentanil as described above. After intubation, the oxygen concentration was raised to $100 \%$ with 1.5 vol \% halothane during the bronchoscopy procedure. A flexible bronchoscope with an external diameter of 3.5 or $4.9 \mathrm{~mm}$ (Pentax, Hamburg, Germany) was wedged in the right middle lobe or one of its segments. BAL was performed with normal saline warmed to body temperature; three times $1 \mathrm{~mL} \cdot \mathrm{kg}^{-1} \mathrm{BW}$ were used in all children. In subjects weighing less than $20 \mathrm{~kg}$, BAL was performed in three portions. In children over $20 \mathrm{~kg}, 20$ $\mathrm{mL}$ portions were instilled up to a total volume of $3 \times 1$ $\mathrm{mL} \cdot \mathrm{kg}^{-1} \mathrm{BW}$. The first sample was considered a primarily bronchial sample; subsequent samples were pooled for analysis. Studies on surfactant composition were performed on the pooled sample only.

\section{Analysis of BALF}

BALF was filtered through sterile gauze and centrifuged at $500 \times \mathrm{g}$ for $10 \mathrm{~min}$. The cell suspension was separated for the analysis of cellular components, which have been reported previously [18]. All studies of surfactant composition were performed on unfrozen specimens of the supernatant. The methodology of the surfactant analysis has been described in detail previously [19]. In summary, phospholipids were extracted from BAL fluids, according to FoLCH et al. [20], using a mixture of chloroform and methanol (2:1). The extract was concentrated under nitrogen at $40^{\circ} \mathrm{C}$ and resuspended in 200 or $300 \mu \mathrm{L}$ chloroform-methanol. After filtering through a squirt filter (Millipore, Eschborn. Germany), $20 \mu \mathrm{L}$ were injected into a high pressure liquid chromatography (HPLC) column. A Gynkotek HPLC-system was used for the analysis. Measurements were performed with an ultraviolet detector at $200 \mathrm{~nm}$ (UV-technique) and with a Sedex 45 light-scattering detector (Sedere, Vitry, France) as mass detector (MD-technique).

Results are presented for the MD-technique and compared to those obtained with the UV-technique.

\section{Surfactant protein A analysis}

A sandwiched enzyme-linked immunosorbant assay (ELISA) was developed using a highly purified recombinant human surfactant protein A (SP-A) antibody, which binds to the globular domain of SP-A. The modification of the methodology yielded a wider range of linear sensitivity which was necessary for the broad range of SP-A values, in particular at the lower side of the distribution. Standardization was performed with human SP-A produced by recombinant deoxyribonucleic acid (DNA) technology (antibodies and the standard solution were kindly provided by Prof. Dr. Schäfer, BYK Gulden, Konstanz, Germany). Immunoassay plates (96 wells) were coated overnight at $4^{\circ} \mathrm{C}$ with a monoclonal antibody directed against human SP-A.

All samples were diluted according to their protein content to a concentration of $5 \mu \mathrm{g} \cdot \mathrm{mL}$ protein. The wells were filled with $100 \mu \mathrm{L}$ diluted samples and standard solutions and incubated at $37^{\circ} \mathrm{C}$ for $4 \mathrm{~h}$. Each plate comprised standard human SP-A in $5-1,000 \mu \mathrm{g} \cdot \mathrm{mL}^{-1}$ dilution; the standard curve was linear in the given range. After appropriate washing the plates were incubated with a rabbit anti-human SP-A polyclonal antibody at $37^{\circ} \mathrm{C}$ for $2 \mathrm{~h}$. The third antibody, conjugated with peroxidase, was a goat anti-rabbit immunoglobulin ( $\mathrm{IgG})$. The peroxidase determination was carried out by adding the substrate orthophenyldiamine (OPD) for 5-10 min, the reaction was subsequently interrupted with $1 \mathrm{M}$ sulphuric acid. The peroxidized OPD was measured at $405 \mathrm{~nm}$ in a plate reader (Labsystems, Multiscan). All measurements were performed three times independently. The precision of this assay has been determined previously utilizing two independent triple assays in BALs of patients in which SP-A ranged $200-8,000 \mathrm{ng} \cdot \mathrm{mL}^{-1}$. The standard deviation over this range was below $10 \%$.

\section{Statistical analysis}

All parameters were tested for normal distribution with the Kolmogorov-Smirnov test. The means, standard deviations (SD) and medians were calculated for all data. The agreement between the light-scattering MD and UV techniques was assessed with the mean difference technique proposed by Bland and Altman [21]. The phospholipid concentrations determined with the two techniques as well as age-related differences in surfactant phospholipids were compared with the Wilcoxon test. 


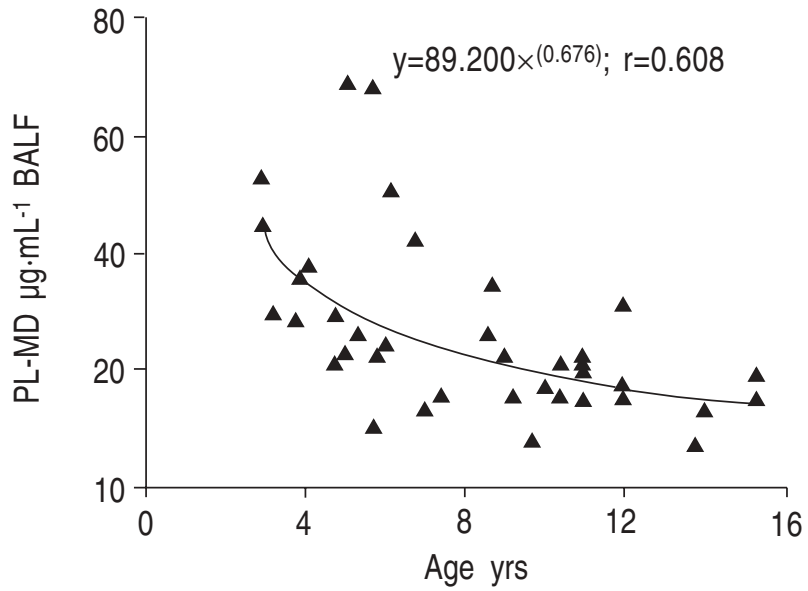

Fig. 1. - Total phospholipid concentrations, as determined by lightscattering mass detector (PL-MD), of bronchoalveolar lavage fluid (BALF) as a function of age. Each triangle represents one individual. The solid line is a power function of best fit.

\section{Results}

No side-effects related to the bronchoalveolar lavage were observed except for a low grade fever in three subjects that subsided spontaneously. The mean \pm SD recovery was $56 \pm 18 \%$ for the total BAL and $64 \pm 19 \%$ for the pooled sample. The relationship between age and total phospholipid (PL) concentration of BALF measured by the light-scattering MD-technique is shown in figure 1. The phospholipid concentration was higher in younger children and decreased with age. Most of these changes had occurred by the age of 8 yrs. If subjects

Table 2. - Comparison of total phospholipid (PL) content in different age groups

\begin{tabular}{ccc}
\hline Age & Total PL & $\mathrm{n}$ \\
& $\mu \mathrm{g} \cdot \mathrm{mL}^{-1}$ & \\
\hline $3-8$ yrs & $35.2 \pm 16.9$ & 18 \\
8-15 yrs & $18.6 \pm 6.7$ & 20 \\
Adults* & $8.1 \pm 3.1$ & 9 \\
\hline
\end{tabular}

Values are presented as mean \pm SD. *: own unpublished results.

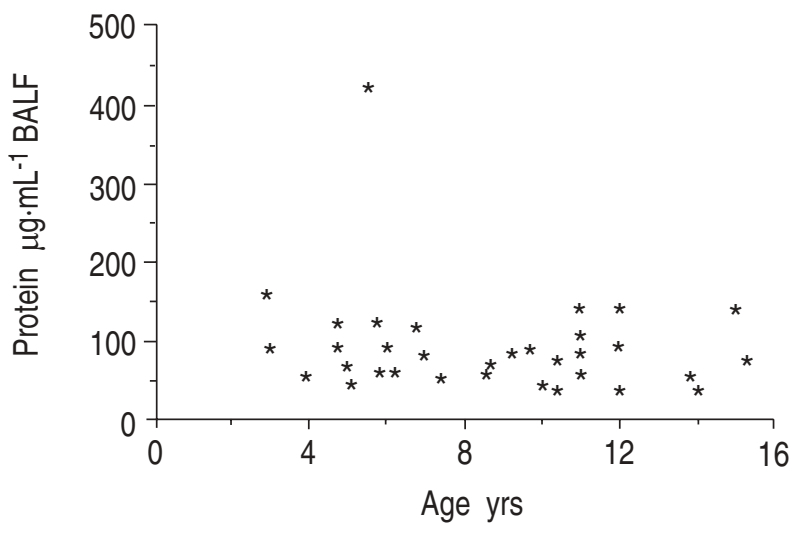

Fig. 2. - Protein concentration of bronchoalveolar lavage fluid (BALF) as a function of age. Each asterisk represents one individual.

were clustered for age, children under $8 \mathrm{yrs}$ of age had approximately twice the amount of PL in their BALF (table 2). The relative distribution of the phospholipid components phosphatidylcholine (PC), phosphatidylglycerol (PG), phosphatidylinositol (PI), phosphatidylethanol (PE) and sphingomyelin (Sph) were independent of age (table 3). Compared to adult reference values, a lower percentage of PG was found in the BALF of children (table 3 ). In contrast to the changes seen in phospholipids, the total protein concentration was constant throughout the age range (fig. 2).

The agreement between the light-scattering MD- and UV-technique for the total phospholipid concentrations in BALF is displayed in figure 3. Total phospholipid concentrations determined by the UV technique were significantly higher $(\mathrm{p}<0.001$, Wilcoxon test). This difference was independent of the absolute phospholipid concentrations (fig. 3).

Surfactant protein A concentrations were highly variable throughout the age range studied (fig. 4). The SPA concentrations were similar to those observed in adults (table 4). However, the range of values was more spread, in particular towards the higher values. A weak but significant correlation was observed between SP-A and the total phospholipid concentration of BALF determined by the light-scattering MD-technique $(\mathrm{r}=0.46 ; \mathrm{p}<0.01)$.

Table 3. - Phospholipid components of total lipid content in healthy subjects

\begin{tabular}{llcccccc}
\hline [Ref.] & Age & $\begin{array}{c}\text { PC } \\
\%\end{array}$ & $\begin{array}{c}\text { PG } \\
\%\end{array}$ & $\begin{array}{c}\text { PI } \\
\%\end{array}$ & $\begin{array}{c}\text { PE } \\
\%\end{array}$ & $\begin{array}{c}\text { Sph } \\
\%\end{array}$ & $\begin{array}{c}\text { PS } \\
\%\end{array}$ \\
\hline Present study & $<8$ yrs & $86.5 \pm 3.3$ & $7.3 \pm 2.4$ & $3.4 \pm 1.5$ & $1.8 \pm 0.5$ & $1.0 \pm 0.5$ & ND \\
Present study & $>8$ yrs & $84.8 \pm 4.7$ & $8.1 \pm 3.3$ & $3.7 \pm 1.5$ & $2.0 \pm 0.7$ & $1.4 \pm 0.5$ & ND \\
Bruch* & Adults & $67.3 \pm 17$ & $16.2 \pm 9.8$ & $7.3 \pm 6.4$ & $3.6 \pm 1.2$ & $5.6 \pm 2.1$ & ND \\
GREGORY [3] & Adults & $76.3 \pm 2.1$ & $11.6 \pm 1.2$ & $3.9 \pm 0.8$ & $3.3 \pm 0.5$ & $1.5 \pm 0.1$ & $0.2 \pm 0.1$ \\
HALLMAN [22] & Adults & $73.0 \pm 2.3$ & $12.4 \pm 0.6$ & $2.7 \pm 0.2$ & $2.6 \pm 0.3$ & $3.7 \pm 0.5$ & $1.0 \pm 1.0$ \\
HoNDA [8] & Adults & $76.7 \pm 1.9$ & $10.8 \pm 1.6$ & $2.6 \pm 0.2$ & $3.5 \pm 1.4$ & $2.0 \pm 0.4$ & $1.1 \pm 0.4$ \\
Low [23] & Adults & $83.9 \pm 6.0$ & $12.4 \pm 3.9$ & $1.0 \pm 1.3$ & $0.4 \pm 0.5$ & ND & $6.0 \pm 0.7$ \\
PISON [5] & Adults & $62.8 \pm 1.1$ & $10.0 \pm 0.7$ & $8.3 \pm 0.4$ & $4.8 \pm 0.9$ & $7.9 \pm 0.5$ & $2.3 \pm 0.9$ \\
RoBinSON [7] & Adults & $72.9 \pm 2.7$ & $13.7 \pm 1.6$ & $4.7 \pm 0.7$ & $4.7 \pm 0.5$ & $1.5 \pm 0.2$ & $2.5 \pm 0.2$ \\
\hline
\end{tabular}

values are presented as mean \pm SD. *: unpublished reference values. PC: phosphatidylcholine; PG: phosphatidylglycerol; PI: phosphatidylinositol; PE: phosphatidylethanol; Sph: sphyngomyelin; ND: not done. 


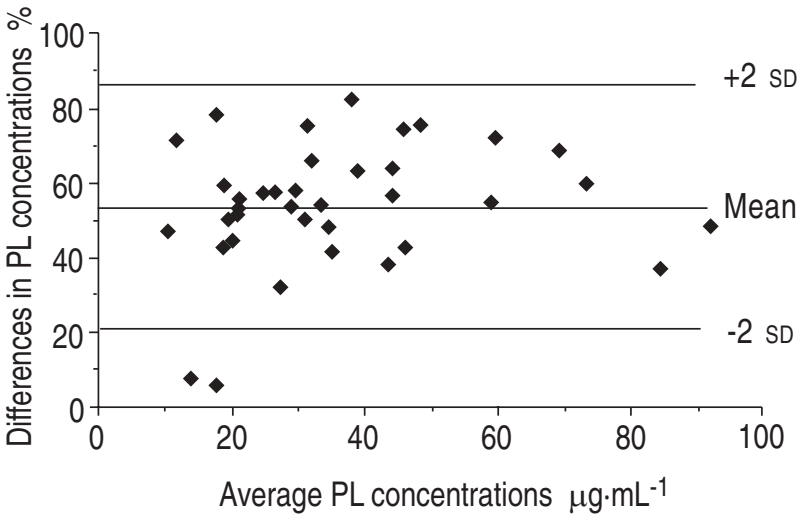

Fig. 3. - Comparison of the total phospholipid (PL) concentrations determined by the ultraviolet (UV) and light-scattering (MD) technique. The average concentrations for the two techniques are displayed on the abscissa; the differences (PL-UV - PL-MD) in percentage of the mean concentration are shown on the ordinate. Each triangle represents one individual. The solid lines represent the average mean \pm SD for the total population. PL concentrations were systematically higher with the UV-technique.

\section{Discussion}

This study provides the first reference values for surfactant components obtained by BAL in children. We could demonstrate an age-dependency of surfactant components in our population of children without pulmonary disease. If subjects are clustered for age (table 2) children aged 3-8 yrs have approximately twice the amount of surfactant as compared to older children. Interestingly, the protein concentrations in BALF showed no age-dependency. Studies in rabbits and monkeys have demonstrated that BALF of new-born animals contains 5-10 times more surfactant material than BALF of adult animals $[24,25]$. A recent study in rats suggested that the higher total phospholipid content in neonates decreases to adult levels during the first 50 days of life [26]. Our results indicate that a similar decrease in the total phospholipid content of BALF occurs in children between 3 and 8 yrs of age. No data for human new-borns are available at the present time, but it is likely that the lipid concentrations are even higher in the neonate. Further studies are warranted to elucidate the changes that are expected to occur in surfactant content between the neo-natal period and 3 yrs of age.

The age dependent shift in lung surfactant observed in our study is not a methodological side-effect due to variable recovery or washing out during the BAL procedure. It may potentially be influenced by the mode of anaesthesia, which was initiated with nitrous oxide and halothane

Table 4. - Surfactant protein A (SP-A) concentrations in BALF of children as compared to healthy nonsmoking adults

\begin{tabular}{ccc}
\hline & \multicolumn{2}{c}{ SP-A } \\
$\mu \mathrm{g} \cdot \mathrm{mL}^{-1}$ & $\mathrm{n}$ \\
\hline Children & $6.9 \pm 9.2(0.07-33.7)$ & 35 \\
Adults* & $3.6 \pm 4.1 \quad(0.16-16)$ & 17 \\
\hline
\end{tabular}

Values are presented as mean $\pm \mathrm{SD}$, and range in parenthesis. *: Bruch et al., unpublished reference values. BALF: bronchoalveolar lavage.

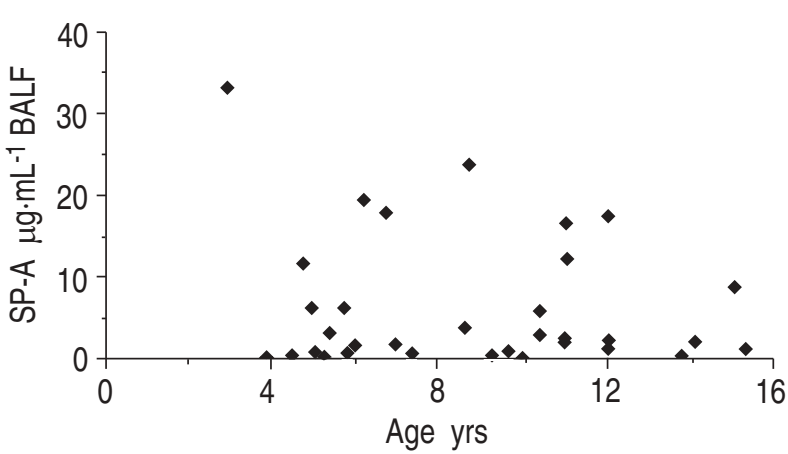

Fig. 4. - Surfactant protein A (SP-A) concentration of bronchoalveolar lavage fluid (BALF) as a function of age. Each triangle represents one individual.

in children younger than $6 \mathrm{yrs}$, whereas in older children anaesthesia was induced intravenously. There is no evidence to suggest that any of the medications used for the induction of anaesthesia has a rapid effect on the surfactant pool in the lung, although halothane is known to reduce surfactant production [27]. However, this effect becomes relevant only after several hours and would not have affected our measurements as BAL was performed immediately after induction of anaesthesia. Moreover, the same regimen (nitrous oxide plus halothane) was used for the maintenance of anaesthesia in both groups. If at all, the longer halothane exposure in younger children would have resulted in lower phospholipid concentrations in this age group; the converse of what we have observed. To account for any potential influence of the mode in which anaesthesia was induced, we have analysed total phospholipid concentrations by stepwise linear regression analysis using 6 yrs as a break-point. Using this methodology, a significant negative correlation between age and PL concentrations is still observed for children older than 6 yrs $(r=-0.5 ; p=0.01)$. These considerations make it unlikely that the differences in phospholipid concentrations observed between younger and older children are caused by the different methods of induction of anaesthesia.

The biological significance of the higher surfactant concentrations in younger children without pulmonary disease is unknown. Lung growth consists of a rapid increase in the number of alveoli in the first years of life [28]. Whilst most of this growth by replication has been completed by the age of 2 yrs, marked changes in alveolar size occur throughout childhood [29]. This is reflected by a decrease in the number of alveoli per millilitre lung tissue from 790 at 3 yrs of age to 390 at 14 yrs of age [29]. As surface tension depends upon alveolar diameter, more surfactant will be needed to maintain a constant surface tension if the individual unit is smaller. It is, therefore, likely that the decrease in surfactant concentration observed in this study is related to this increase in alveolar size during childhood, since less surface active material is necessary to reduce the surface tension in a bigger alveolus.

Regarding disease states, it is well-known that deficiency of surfactant in the neonate causes the respiratory distress syndrome (RDS), which is amenable to replacement therapy with exogenous surfactant [2]. With the 
exception of the new-born infant with RDS, little information is available about the lipid components on the alveolar surface in children. Studies in infants with bronchopulmonary dysplasia (BPD) have shown that phosphatidylcholine (PC), the most prevalent component of surfactant, is reduced in BALF of these infants [16]. Tracheal aspirates have been used for the analysis of surfactant in ventilated neonates [30]. Whilst tracheal aspirates are unlikely to render reliable information about the surfactant content of the epithelial lining fluid, phosphatidylcholine was found to be lower in neonates who subsequently developed RDS. However, PC in these tracheal aspirates was not found to be a good predictor for the development of chronic lung disease [30]. The total phospholipid content of BALF is reduced in children dying of sudden infant death syndrome [14], but it is unclear whether this is a primary phenomenon or secondary to phospholipases produced by infectious organisms [15]. Chronic bacterial infection is also the cause of reduced surfactant concentrations in patients with cystic fibrosis, who are chronically colonized with Pseudomonas aeruginosa which is known to produce significant amounts of phospholipase $[12,13]$.

Abnormalities of surfactant function have been described in two children with recurrent cyanotic episodes but the overall frequency of these changes is unknown [17]. As surfactant plays an important role in the initial host defence process [31], it is likely that changes in its composition occur relatively early in pulmonary disorders. Studies of the surfactant composition, therefore, bear the potential to increase our understanding of the pathogenesis of paediatric lung diseases.

Surfactant protein A was found to be highly variable in this group of children without pulmonary disease. This is in concordance with studies in adults where a wide range of concentrations has been observed in healthy subjects, although significant difference have been observed between healthy individuals and patients with pulmonary disease [32-34]. We have observed a weak correlation between SP-A and the total phospholipid content for the group as a whole; however, the r-value of 0.46 would imply that only $20 \%$ of the variability is explained by the variation in phospholipid concentrations. Whether SP-A will be a useful parameter to differentiate between healthy subjects and children with pulmonary disease remains to be determined.

In summary, we have studied the phospholipid composition of bronchoalveolar lavage fluid in 38 children without lung disease aged $3-15$ yrs. The total lipid content was higher in younger children and decreased with age. These data provide a first insight into the phospholipid composition of the epithelial lining fluid in children. Further studies will address whether specific profiles of surfactant components can be observed in paediatric lung diseases.

\section{References}

1. Avery ME, Mead J. Surface properties in relation to atelectasis and hyaline membrane disease. Am J Dis Child 1959; 97: 517-523.
2. Jobe A, Ikegami M. Surfactant for the treatment of respiratory distress syndrome: state of the art. Am Rev Respir Dis 1987; 136: 1256-1275.

3. Gregory TJ, Longmore WJ, Moxley MA, et al. Surfactant: chemical composition and biophysical activity in acute respiratory distress syndrome. J Clin Invest 1991; 88: 1976-1981.

4. Lewis JF, Jobe AH. Surfactant and the adult respiratory distress syndrome: state of the art. Am Rev Respir Dis 1993; 147: 218-233.

5. Pison U, Seeger W, Buchhorn R, et al. Surfactant abnormalities in patients with respiratory failure after multiple trauma. Am Rev Respir Dis 1989; 140: 1034-1039.

6. Pison U, Obertacke U, Brand M, et al. Altered pulmonary surfactant in uncomplicated and septicemia-complicated courses of acute respiratory failure. J Trauma 1990; 30: 19-26.

7. Robinson PC, Watters LC, King TE, Mason RJ. Idiopathic pulmonary fibrosis: abnormalities in bronchoalveolar lavage fluid phospholipids. Am Rev Respir Dis 1988; 137: 585-591.

8. Honda Y, Tsunematsu K, Suzuki A, Akino T. Changes in phospholipids in bronchoalveolar lavage fluid of patients with interstitial lung diseases. Lung 1988; 166: 293-301.

9. Hughes DA, Haslam PL. Changes in phosphatidylglycerol in bronchoalveolar lavage fluids from patients with cryptogenic fibrosing alveolitis. Chest 1989; 95: 82-89.

10. Escamilla R, Prevost MC, Hermant C, Caratero A, Cariven C, Krempf M. Surfactant analysis during Pneumocystis carinii pneumonia in HIV-infected patients. Chest 1992: 101: $1558-1562$.

11. Hoffmann AGD, Lawrence MG, Ognibene FP, et al. Reduction of pulmonary surfactant in patients with human immunodeficiency virus infection and Pneumocystis carinii pneumonia. Chest 1992: 102: 1730-1736.

12. Gilljam H, Andersson O, Ellin A, Robertson B, Strandvik B. Composition and surface properties of the bronchial lipids in adult patients with cystic fibrosis. Clin Chim Acta 1988; 176: 29-38.

13. Holm BA, Keicher L, Liu M, Sokolowski J, Enhorning G. Inhibition of pulmonary surfactant function by phospholipases. J Appl Physiol 1991; 71: 317-321.

14. Morley CJ, Hill CM, Brown BD, Barson AJ, Davis JA. Surfactant abnormalities in babies dying of the sudden infant death syndrome. Lancet 1982; i: 1320-1322.

15. James D, Berry PJ, Fleming P, Hathaway M. Surfactant abnormality and the sudden infant death syndrome: a primary or secondary phenomenon? Arch Dis Child 1990; 65: 774-778.

16. Clement A, Masliah J, Housset B, et al. Decreased phosphatidylcholine content in bronchoalveolar lavage fluid of children with bronchopulmonary dysplasia. Ped Pulmonol 1987; 3: 67-70.

17. Hills BA, Masters JB, O'Duffy JF. Abnormalities of surfactant in children with recurrent cyanotic episodes. Lancet 1992; 339: 1323-1324.

18. Ratjen F, Bredendiek M, Brendel M, Meltzter S, Costabel U. Differential cytology of bronchoalveolar lavage fluid in normal children. Eur Respir J 1994; 7: 1865-1870.

19. Bruch J, Gono E, Malkusch W, Rehn B. Improved method for quantitative analysis of lung surfactant phospholipids in bronchoalveolar lavage fluids by high performance liquid chromatography. Clin Chim Acta 1994; 231: 193-204.

20. Folch J, Lees M, Stanley GHS. A simple method for the isolation and purification of total lipids from animal tissues. J Biol Chem 1957; 226: 497-509. 
21. Bland JM, Altman DG. Statistical methods for assessing agreement between two methods of clinical measurement. Lancet 1986; i: 307-309.

22. Hallman M, Maassilta P, Sipilä I, Tahvanainen J. Evidence of lung surfactant abnormality in respiratory failure. $J$ Clin Invest 1982; 79: 673-683.

23. Low RB, Davis GS, Giancola MS. Biochemical analysis of bronchoalveolar lavage fluids of healthy human volunteer smokers and nonsmokers. Am Rev Respir Dis 1978; 119: 863-875.

24. Jackson JC, Palmer S, Wilson CB, et al. Postnatal changes in lung phospholipids and alveolar macrophages term newborn monkeys. Respir Physiol 1988; 73: 289-300.

25. Jobe A, Ikegami M, Jacobs H. Changes in the amount of lung and airway phosphatidylcholine in 0.5-12 day old rabbits. Biochim Biophys Acta 1981; 664: 182-187.

26. Ohashi T, Pinkerton K, Ikegami M, Jobe AH. Changes in alveolar surface area, surfactant protein A and saturated phosphatidylcholine with postnatal rat lung growth. Ped Res 1994; 35: 685-689.

27. Molliex S, Crestani B, Dureuil B, et al. Effects of halothane on surfactant biosynthesis by rat alveolar type II cells in primary culture. Anesthesiology 1994; 81: 668-676.
28. Dunnill MS. Postnatal growth of the lung. Thorax 1962; 17: 329-333.

29. Davis G, Reid L. Growth of the alveoli and pulmonary arteries in childhood. Thorax 1970: 25: 669-681.

30. Ashton MR, Postle AD, Hall MA, Smith SL, Kelly FJ, Normand ICS. Phosphatidylcholine composition of endotracheal tube aspirates of neonates and subsequent respiratory disease. Arch Dis Child 1992; 67: 378382.

31. Curti PC, Genghini M. Role of surfactant in alveolar defense against inhaled particles. Respiration 1989; 55 (Suppl. 1): 60-67.

32. Van de Graaf EA, Jansen HM, Lutter R, et al. Surfactant protein A in bronchoalveolar lavage fluid. J Lab Clin Med 1992; 120: 252-263.

33. Baughman RP, Sternberg RI, Hull W, Buchsbaum JA, Whitsett J. Decreased surfactant protein A in patients with bacterial pneumonia. Am Rev Respir Dis 1992; 147: 653-657.

34. Hamm H, Lührs J, Guzman y Rotaeche J, Costabel U, Fabel H, Bartsch W. Elevated surfactant protein A in bronchoalveolar lavage fluid from sarcoidosis and hypersensitivity pneumonitis patients. Chest 1994; 106: 17061710. 